\title{
Hospitalisation rates and predictors in people with dementia: a systematic review and meta-analysis
}

\author{
Hilary Shepherd ${ }^{1}$, Gill Livingston ${ }^{1,2}$, Justin Chan ${ }^{1}$ and Andrew Sommerlad ${ }^{1,2^{*}}$ (D)
}

\begin{abstract}
Background: Hospitalisation is often harmful for people with dementia and results in high societal costs, so avoidance of unnecessary admissions is a global priority. However, no intervention has yet reduced admissions of community-dwelling people with dementia. We therefore aimed to examine hospitalisation rates of people with dementia and whether these differ from people without dementia and to identify socio-demographic and clinical predictors of hospitalisation.
\end{abstract}

Methods: We searched MEDLINE, Embase, and PsycINFO from inception to 9 May 2019. We included observational studies which (1) examined community-dwelling people with dementia of any age or dementia subtype, (2) diagnosed dementia using validated diagnostic criteria, and (3) examined all-cause general (i.e. non-psychiatric) hospital admissions. Two authors screened abstracts for inclusion and independently extracted data and assessed included studies for risk of bias. Three authors graded evidence strength using Cochrane's GRADE approach, including assessing for evidence of publication bias using Begg's test. We used random effects meta-analysis to pool estimates for hospitalisation risk in people with and without dementia.

Results: We included 34 studies of 277,432 people with dementia: 17 from the USA, 15 from Europe, and 2 from Asia. The pooled relative risk of hospitalisation for people with dementia compared to those without was 1.42 (95\% confidence interval $1.21,1.66)$ in studies adjusted for age, sex, and physical comorbidity. Hospitalisation rates in people with dementia were between 0.37 and 1.26/person-year in high-quality studies. There was strong evidence that admission is associated with older age, and moderately strong evidence that multimorbidity, polypharmacy, and lower functional ability are associated with admission. There was strong evidence that dementia severity alone is not associated.

Conclusions: People with dementia are more frequently admitted to hospital than those without dementia, independent of physical comorbidities. Future interventions to reduce unnecessary hospitalisations should target potentially modifiable factors, such as polypharmacy and functional ability, in high-risk populations.

Keywords: Hospitalisation, Dementia, Healthcare utilisation, Risk factors, Prognosis

\footnotetext{
* Correspondence: a.sommerlad@ucl.ac.uk

${ }^{1}$ Division of Psychiatry, University College London, 6th Floor, Maple House,

149 Tottenham Court Road, London W1T 7NF, UK

${ }^{2}$ Camden and Islington NHS Foundation Trust, 4 St Pancras Way, London

NW1 OPE, UK
}

(c) The Author(s). 2019 Open Access This article is distributed under the terms of the Creative Commons Attribution 4.0 International License (http://creativecommons.org/licenses/by/4.0/), which permits unrestricted use, distribution, and reproduction in any medium, provided you give appropriate credit to the original author(s) and the source, provide a link to the Creative Commons license, and indicate if changes were made. The Creative Commons Public Domain Dedication waiver (http://creativecommons.org/publicdomain/zero/1.0/) applies to the data made available in this article, unless otherwise stated. 


\section{Background}

The number of older people is expected to rise throughout the century, with the number of people with dementia rising in parallel [1]. Hospital admissions can be harmful and distressing for people with dementia who are less likely to receive adequate pain relief [2], more likely to receive potentially harmful medication [3], have a higher risk of delirium than those without dementia [4], and commonly decline functionally during admission [5]. Avoidable admissions are more frequent for people with dementia [6] and readmission is common [7]. Admissions are costlier for people with dementia than those without [8], and pressures on hospitals to reduce admission length could also mean that people with dementia are prematurely discharged from hospital into long-term care [9].

In this systematic review, we aimed to examine the rates of all general hospitalisations of people with dementia, whether these differ from those without dementia, and to identify socio-demographic and clinical predictors of admission. Understanding these would help to plan services for future increasing numbers of people with dementia. Previously designed interventions to reduce hospitalisations in people with dementia have not been found to be effective [10]. Identifying admission predictors may elucidate modifiable risk factors which future interventions could target in populations most likely to benefit.

\section{Aims}

The following are the aims of the study:

- To compare hospitalisation risk in people with dementia to people without dementia

- To identify general hospital admission rates of people with dementia

- To examine demographic or clinical factors associated with higher hospital admission risk

\section{Methods}

We prospectively registered the study protocol with PROSPERO (registration number CRD42018091722) (Additional file 2).

\section{Search strategy}

We searched MEDLINE, Embase, and PsycINFO, including grey literature. The initial search was completed on 18 April 2018 and updated on 22 October 2018 and 9 May 2019 with no date or language restrictions. The search terms related to people with dementia, hospitalisation, and observational studies, using the SIGN filters for observational studies; the full search strategy is in Additional file 1: Table S1. We hand-searched included papers' reference lists and contacted experts in the field to ensure a comprehensive review.

\section{Inclusion and exclusion criteria}

We included observational studies which:

- Examined populations of people with dementia (any age or dementia subtype)

- Included clinical, research, or register populations of people with dementia, diagnosed using validated diagnostic criteria, e.g. International Statistical Classification of Diseases and Related Health Problems 10th revision, Diagnostic and Statistical Manual of Mental Disorders 5th edition, National Institute of Neurological and Communicative Disorders and Stroke, and the Alzheimer's Disease and Related Disorders criteria

- Examined all-cause general (i.e. non-psychiatric) hospital admissions, providing sufficient data to examine the hospitalisation rates or potential risk factors

We excluded papers which:

- Examined populations who predominantly resided in long-term nursing care facilities

- Did not adequately delineate dementia, e.g. defined dementia by cognitive test score cut-off or solely by acetylcholinesterase inhibitor prescription. We included studies which supplemented register-derived dementia diagnosis by using medication prescription as an additional marker of dementia status

- Studied general populations of older people when it was impossible to separate out those with dementia

- Recruited study participants upon hospitalisation, as this prevents identification of factors leading to hospitalisation

\section{Screening papers}

After excluding duplicate papers, one researcher (HS) screened the titles and abstracts using the eligibility criteria. A random $10 \%$ sample was independently reviewed for inclusion by a second researcher (JC); initial concordance regarding the study inclusion was $87 \%$, and disagreements were resolved by a discussion with a third researcher (AS). Consensus on the inclusion of all studies was agreed by two researchers (HS, AS) with any disagreements resolved in a discussion with a third (GL).

\section{Data extraction and synthesis}

Where available, the following information was extracted from included studies using a pre-piloted data extraction form (Additional file 1: Table S2): author, year and country of setting, participant number, mean age, sex distribution, 
method of diagnosis, study length and average followup time, average severity of dementia. Extracted outcome data were adjusted relative risk of hospitalisation in people with dementia compared to people without dementia and covariates included in fully adjusted models; percentage or rate of hospitalisation in people with dementia; socio-demographic or clinical factors examined as potential predictors of hospital admission; classification of factors and relative risk for their association with admission and covariates included in relative risk models. Two authors (HS and AS) independently extracted the outcome data.

We extracted data on admissions where the rate (per person-years (py)) or percentage of participants admitted to hospital was presented. Where the rate or proportion admitted was not provided, but raw data was available, we calculated the hospitalisation rate (number of hospitalisations/py) and/or percentage of participants admitted during study follow-up.

We prioritised obtaining the risk estimates provided for all-cause hospitalisation and, where this was not available, for admissions defined as preventable or ambulatory care sensitive conditions (ACSC), or for emergency rather than elective hospital admissions. Admissions caused by, for example, angina, infection, dehydration, or diabetes are deemed potentially avoidable, as proactive community care could prevent the need for a hospital stay [11, 12]. For studies with unclear data, we requested clarification directly from the study authors and included them in our primary analyses if this was received.

\section{Data analysis}

\section{Quality assessment and analysis}

Two researchers (HS, AS) assessed the risk of bias in individual papers using a modified version of the Newcastle-Ottawa Scale (NOS) for assessing the quality of cohort studies [13]. This considered definition of exposure, method of outcome ascertainment, selection and measurement bias, and confounding. Concordance on quality rating criteria was $89 \%$, and consensus was reached through discussion in cases of disagreement on individual rating criteria. Full details of ratings are in Additional file 1: Table S3.

\section{Evidence grading}

We then used the Cochrane Collaboration's Grading of Recommendations, Assessment, Development and Evaluation (GRADE) approach to rate the confidence in the estimates given [14]. Grades of high, moderate, low, or very low were allocated based on the research team's (AS, HS, GL) assessment of seven criteria: (1) risk of bias in individual studies assessed using NOS, (2) inconsistency (unexplained heterogeneity of results or non- overlapping 95\% confidence intervals across studies), (3) indirectness (limited generalisability of the study populations), (4) imprecision (number of study participants and confidence intervals (CI) around the effect), (5) evidence of publication bias, (6) large magnitude of effect, and (7) evidence of dose-response relationship. Strength of evidence was graded down if factors 1-5 were noted and graded up if factor 6 or 7 was seen. To rate the precision, we performed a power calculation to find the number of participants needed to find a hospitalisation rate of $37 \%$, as 0.37 hospitalisations/py was the lowest rate extracted from a paper at low risk of bias according to NOS, with $80 \%$ power and a significance level of $5 \%$. Consequently, studies comprising $>349$ participants with dementia were classed as precise. To rate the publication bias, we used Begg's test when three or more studies measured an exposure in the same way, with $p \leq 0.10$ indicating risk of publication bias [15], using STATA 14.

\section{Statistical analysis}

We provide a narrative synthesis of findings from the included studies. For estimates of the risk of hospitalisation for people with dementia compared to those without in studies which adjusted for at least age, sex, and physical comorbidity, we used random effects meta-analysis to pool the results. Random effects models are appropriate where there is potential heterogeneity in study populations [16] and allows a combination of different measures of relative risk, e.g. hazard ratio and odds ratio [17]. We measured heterogeneity between studies using the $I^{2}$ statistic and considered a priori that $I^{2}>50 \%$ indicated substantial heterogeneity. We judged we were unable to metaanalyse the findings on predictors of hospital admission as these frequently used heterogeneous exposure measures.

\section{Results}

We found 34 papers including a total of 277,432 people with dementia. The Preferred Reporting Items for Systematic Review and Meta-Analysis (PRISMA) diagram (Fig. 1) describes the results of the search and reasons for excluding studies [18]. Thirty-four included papers reported data from 1991 to 2016 and comprised 17 from the USA, five from England, three from France, three from Sweden, two from Finland, and one each from Taiwan, Germany, Hong Kong, and Scotland (Table 1). Five papers studied sub-populations: two were people with dementia at end of life, and one each of people with dementia and cancer, people with dementia and intellectual disability, and people with dementia and dysphagia, and we considered these separately. 


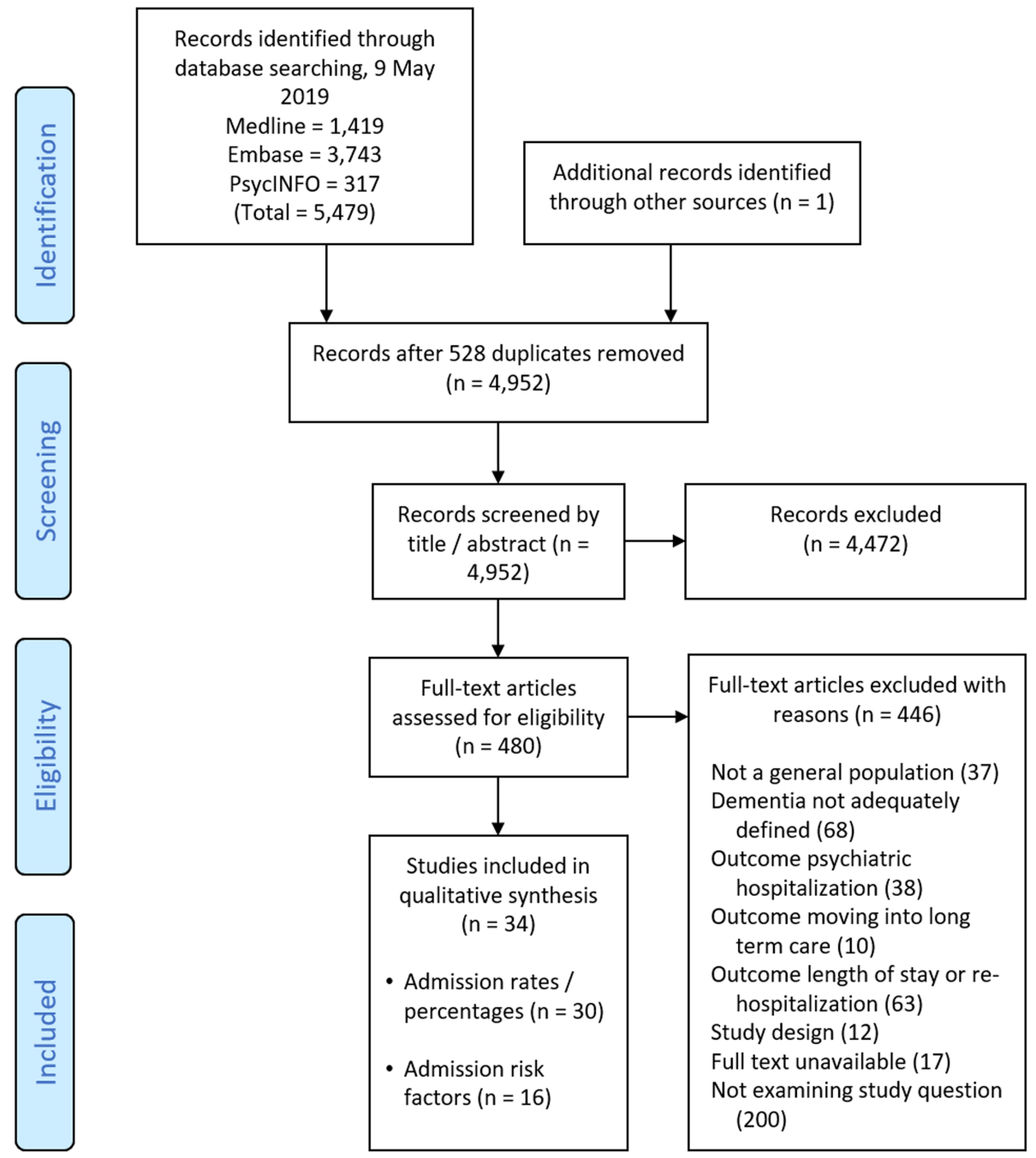

Fig. 1 PRISMA flow diagram of included studies

\section{Comparison to people without dementia}

Six studies examined the risk of hospital admission in people with dementia compared to people without dementia, adjusting for at least age, sex, and physical comorbidity. Relative risk (RR) estimates in these papers ranged from 1.08 to 2.3. Figure 2 presents pooled relative risk estimate for hospitalisation in people with dementia compared to those without ( $R R=1.42$ (95\% CI 1.21, 1.66), $p<$ $\left.0.001, I^{2}=86.3 \%\right)$. There was a consistent direction of effect, and estimates were of similar magnitude. Begg's test indicated a low risk of bias, so the overall strength of this evidence was graded as high (full data on the assignment of GRADE evidence strength is in Additional file 1: Table S4). Four other studies [23, 34, 41, 46] did not adjust for comorbidity and two of these found notably higher relative risk estimates (3.68 and 4.19), but we did not include these in our meta-analysis as we wished to examine the hospitalisation risk accounting for the potential confounding effect of physical illness; we were unable to include one other study which did not provide a specific $p$ value or confidence interval [44].

Two studies examined hospitalisation risk for people with dementia at the end of life with one Taiwanese register study of people in the last year of life reporting RR for admission 1.14 (0.91-1.41) and the other study of Finnish people with dementia in the final 2 years of life showing lower admission risk $(R R=0.33(0.31-0.35))$. There was low confidence in the evidence as the studies are of moderate and low quality respectively, and they present contradictory estimates $[47,48]$.

\section{Rates of hospitalisation per year}

Table 2 displays the rates of hospital admissions in people with dementia. The studies with the lowest risk of bias found the rate to be between 0.37 /py and 1.26/ py. Among studies that used research cohorts or clinical 


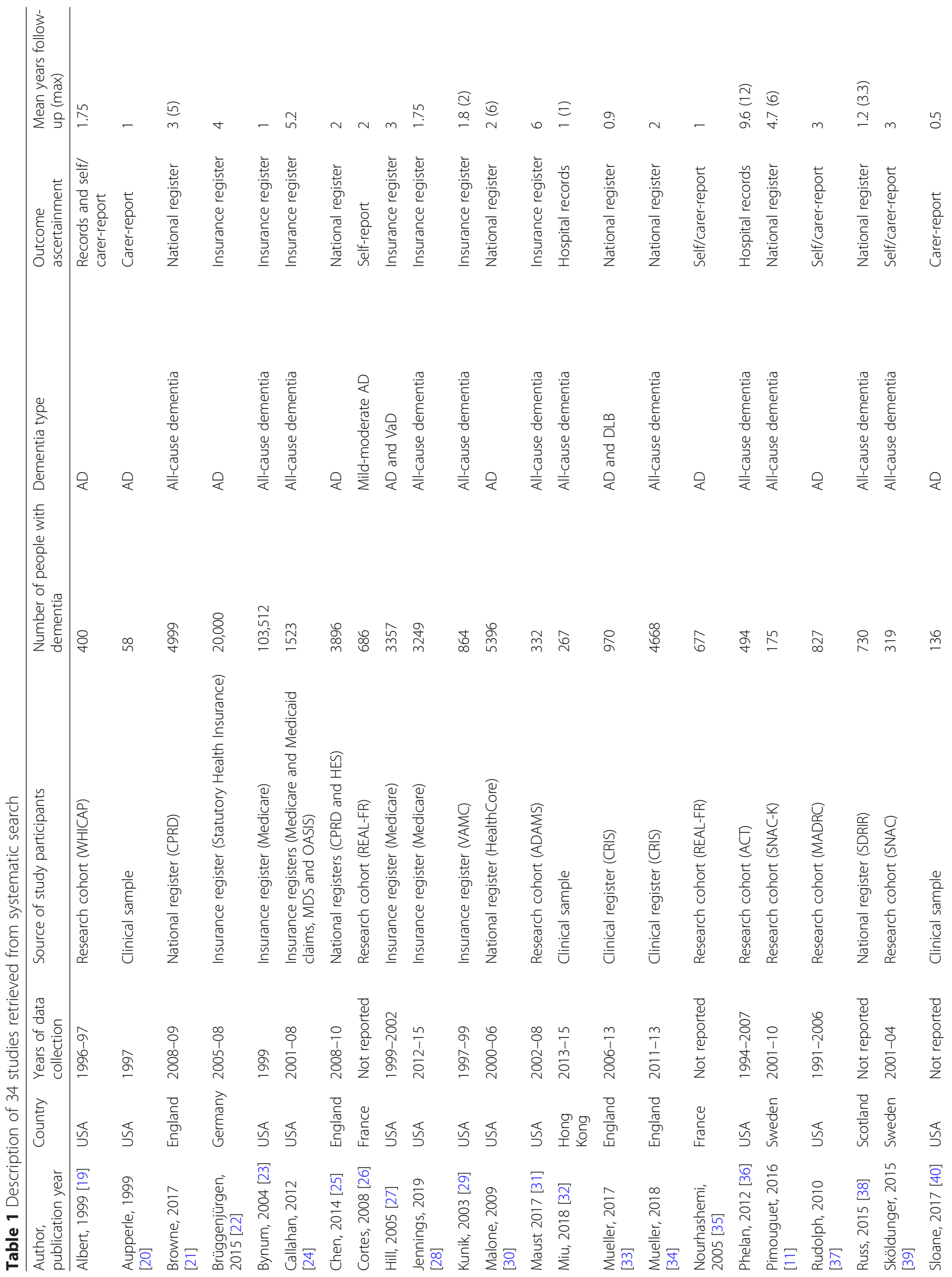


Shepherd et al. BMC Medicine

(2019) $17: 130$

Page 6 of 13

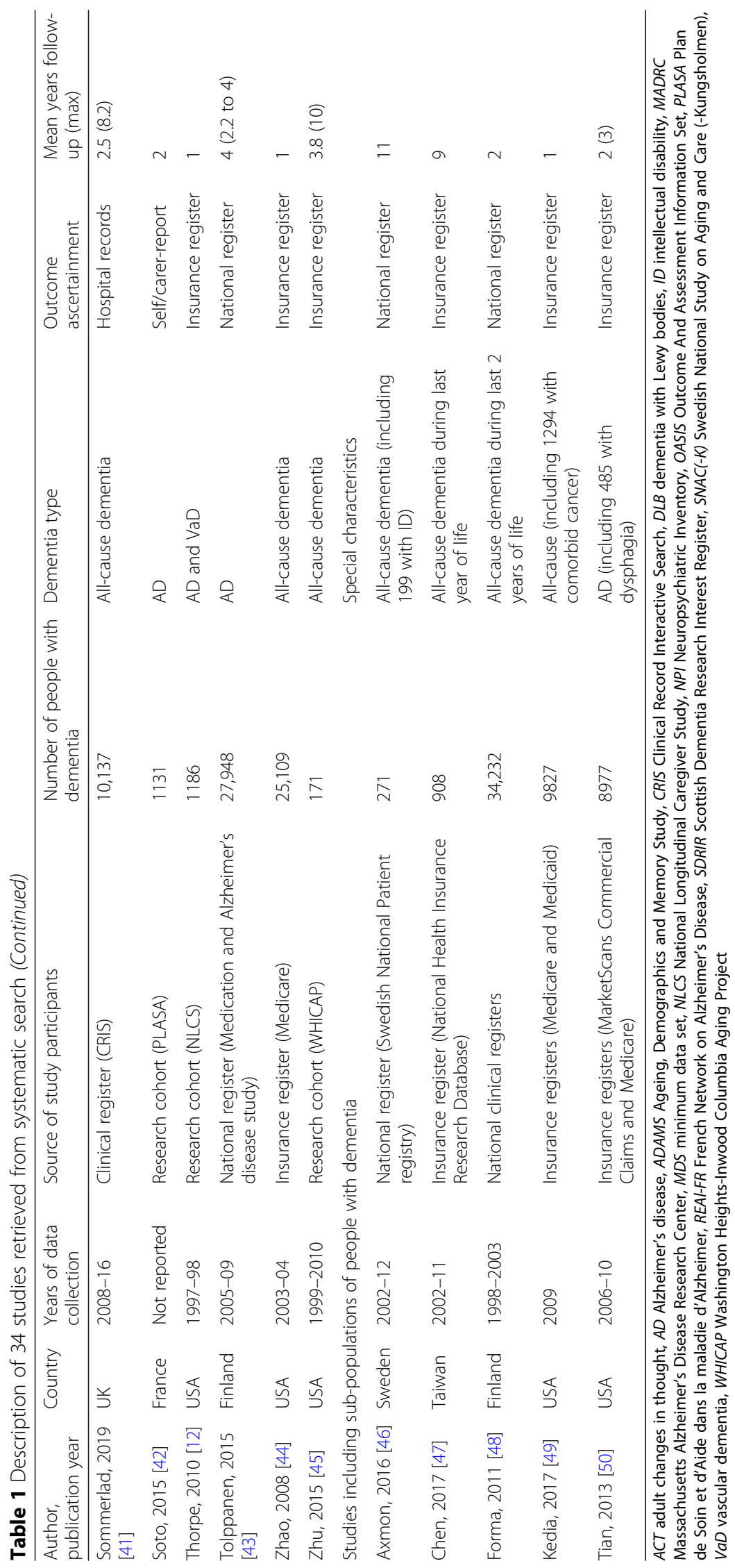




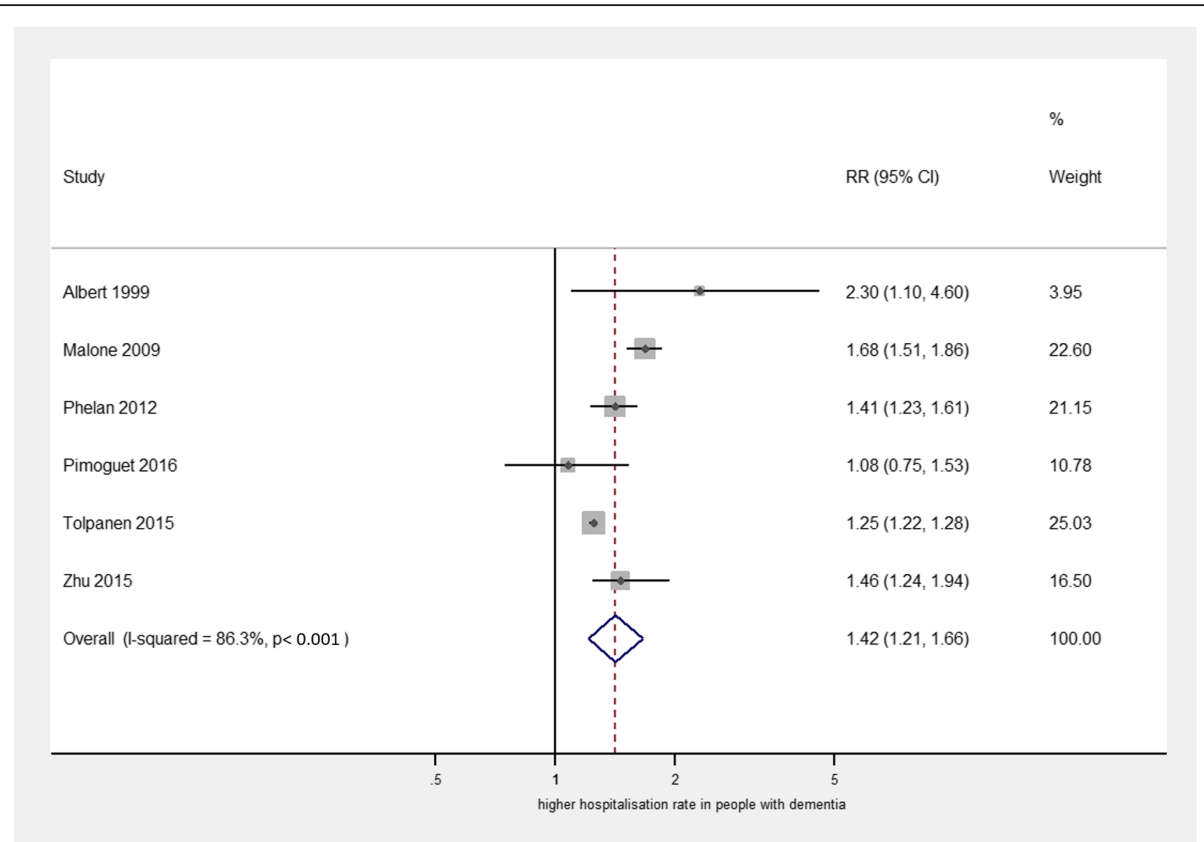

Fig. 2 Forest plot of studies examining relative risk of hospitalisation for people with dementia compared to those without dementia, adjusted for age, sex, and physical comorbidity. Note: weights are derived from random effects meta-analysis

samples, the rate ranged from $0.16 /$ py to $0.48 / \mathrm{py}$, whereas in studies using national registers, the rate ranged from $0.23 /$ py to $1.26 / \mathrm{py}$. Where available, the percentage of participants hospitalised was also extracted (Additional file 1: Table S5), and in four studies at low risk of bias which followed participants for 1 year, 26$65 \%$ of study participants were admitted.

\section{Risk factors associated with hospitalisation}

Figure $3 \mathrm{a}$ and $\mathrm{b}$ show the associations between sociodemographic and clinical factors and hospitalisation in people with dementia, and each risk factor has been allocated a grade according to the confidence in the estimates. Full detail of the criteria used to assign GRADE levels of evidence strength for each risk factor is in Additional file 1: Table S6.

\section{Factors relating to the person with dementia associated with admission}

Older age was consistently associated with risk of hospitalisation across six studies; the odds ratio (OR) for hospitalisation with each additional year of age was OR = 1.02 in one study and OR $=1.04$ in another [12, 30], and findings were consistent when considering people aged $>95$ compared to $<75$ (rate ratio = 1.66) [21]. After considering the quality of individual studies, overall consistency, and absence of evidence of publication bias $(p=0.60)$, we rated confidence in the effect of older age on increasing hospitalisation risk as high.
Having multimorbidities was associated with hospitalisation across six studies. A consistently large effect increased confidence in the finding, and there was no evidence of publication bias $(p=0.60)$. However, point estimates and confidence intervals around estimates varied widely, for instance, having other illnesses compared to none increased odds of hospitalisation hazard ratio $(\mathrm{HR})=1.28$ in one study, $\mathrm{OR}=1.47$ in another, and $\mathrm{HR}=1.87$ in the third [37-39]. Therefore, confidence was graded as moderate.

There was moderate confidence in the association of lower level of functional ability with hospitalisation risk as four studies found a consistent direction of results with moderate magnitude ( $R R=1.08$ to 1.27 ), indicating that less independence contributed to a higher risk of hospitalisation. Similarly, the use of $\geq 7$ (compared to 03) medications was significantly associated with a higher risk of admission in one high-quality (i.e. low risk of bias) study $(\mathrm{HR}=1.32)$, and there was evidence of a dose-response effect [34], resulting in moderate confidence. There was also moderate confidence in the finding that severity of dementia was not associated as three studies at low risk of bias consistently found no effect of dementia severity on hospitalisation [37, 38, 51].

\section{Factors relating to the primary caregiver associated with admission}

There was low or very low confidence in all factors relating to the caregiver as only one study examined each association. 
Table 2 Hospitalisation rates of people with dementia

\begin{tabular}{|c|c|c|c|}
\hline $\begin{array}{l}\text { Author } \\
\text { Publication year }\end{array}$ & Country & $\begin{array}{l}\text { Years of } \\
\text { study }\end{array}$ & $\begin{array}{l}\text { Hospitalisation rate } \\
\text { (per person year) }\end{array}$ \\
\hline $\begin{array}{l}\text { Brüggenjürgen } \\
2015\end{array}$ & Germany & $2005-08$ & 0.51 \\
\hline $\begin{array}{l}\text { Mueller } \\
2017\end{array}$ & England & $2006-13$ & 0.95 \\
\hline $\begin{array}{l}\text { Phelan } \\
2012\end{array}$ & USA & 1994-2007 & 0.41 \\
\hline $\begin{array}{l}\text { Pimouguet } \\
2016\end{array}$ & USA & 2001-10 & 0.37 \\
\hline $\begin{array}{l}\text { Sommerlad } \\
2019\end{array}$ & UK & $2008-16$ & 1.26 \\
\hline $\begin{array}{l}\text { Tolppanen } \\
2015 \\
\end{array}$ & Finland & 2005-09 & 1.17 \\
\hline $\begin{array}{l}\text { Callahan } \\
2012\end{array}$ & USA & 2001-08 & 0.88 \\
\hline $\begin{array}{l}\text { Jennings } \\
2019\end{array}$ & USA & $2012-15$ & 0.50 \\
\hline $\begin{array}{l}\text { Hill } \\
2005\end{array}$ & USA & $1999-2002$ & 0.53 \\
\hline $\begin{array}{l}\text { Rudolph } \\
2010\end{array}$ & USA & 1991-2006 & 0.16 \\
\hline $\begin{array}{l}\text { Sloane } \\
2017\end{array}$ & USA & $\begin{array}{l}\text { Not } \\
\text { reported }\end{array}$ & 0.48 \\
\hline $\begin{array}{l}\text { Soto } \\
2015\end{array}$ & France & $\begin{array}{l}\text { Not } \\
\text { reported }\end{array}$ & 0.27 \\
\hline $\begin{array}{l}\text { Tian } \\
2013\end{array}$ & USA & $2006-10$ & 0.23 \\
\hline
\end{tabular}

Bold outline indicates studies with lowest risk of bias

\section{Discussion}

This is the first comprehensive systematic review of the rates and risk factors for hospitalisation in people with dementia. We found with high confidence an increased rate of hospitalisation of people with dementia compared to people without dementia. The pooled relative risk of hospitalisation for people with dementia compared to those without was 1.42 (95\% CI 1.21-1.66) in studies adjusted for age, sex, and physical comorbidity. The increased risk of hospitalisation of people with dementia, in moderate or high-quality studies, ranged from 1.08 to 2.30 . This wide range suggests that hospitalisation risk may be modified by differing healthcare provision. High-quality studies found general hospital admission rates for people with dementia to be between 0.37 and $1.26 / \mathrm{py}$. There is strong evidence that older age is associated with admission and moderate evidence that presence of physical comorbidities, having a lower functional level and taking $\geq 7$ medications, is associated with admission, while there was strong evidence that dementia severity alone is not associated with hospitalisation.

The organisation of health and social systems in different countries may affect hospitalisation risk, or differences in the relative risk for those with and without dementia could be due to the adjustments in analyses. One study that did not adjust for physical comorbidities found a risk of $\mathrm{OR}=3.68$ for people with dementia compared to those without, suggesting that worse physical illness explains part of the increased hospitalisation risk of people with dementia [52]. This study also analysed the hospitalisation risk according to the numbers of chronic conditions and found that dementia increased the risk of admission whether or not people had other long-term illnesses, no 


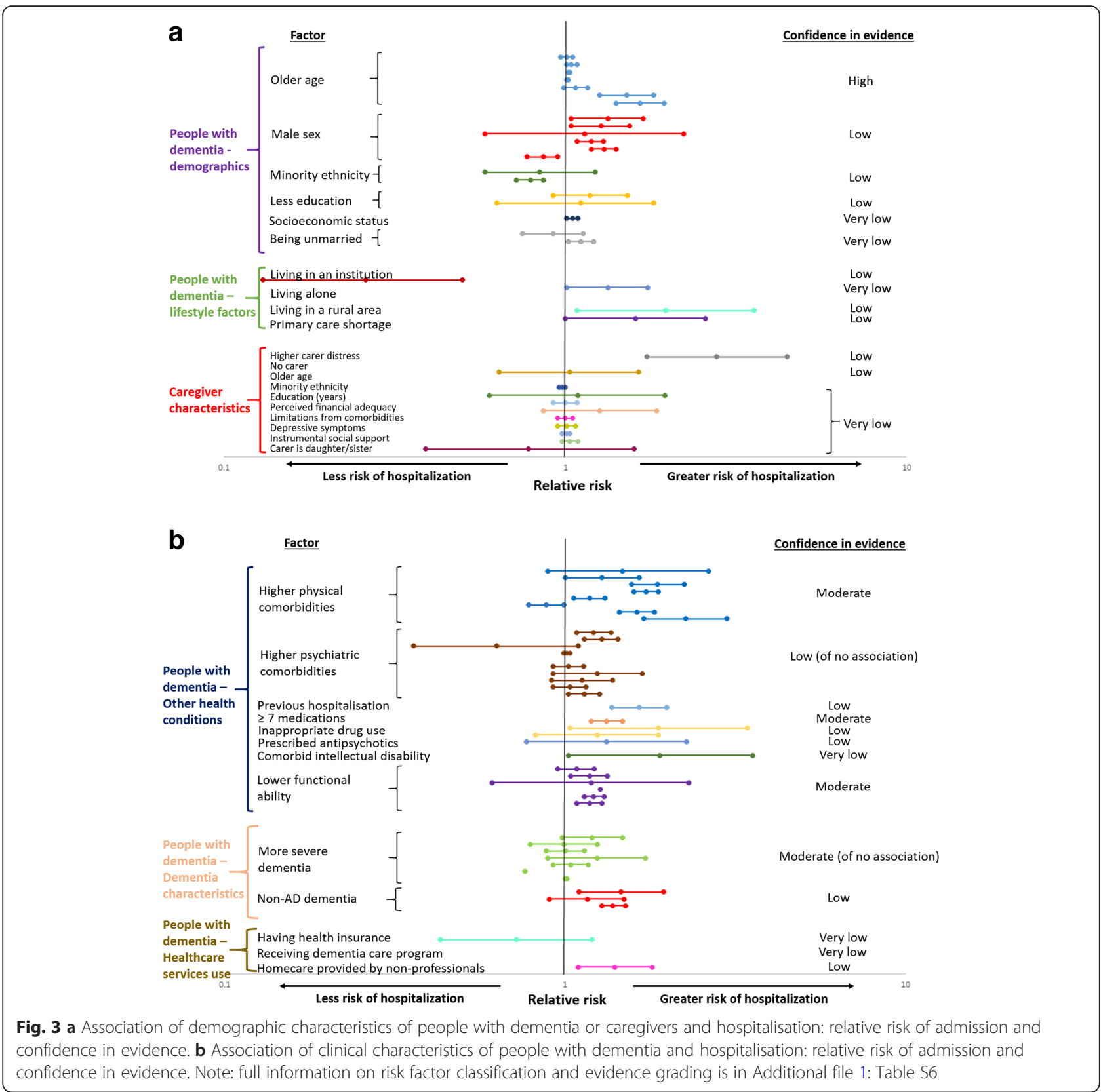

other long-term conditions ( $R R=5.92,5.60-6.27$ ), or five $(\mathrm{RR}=2.87,2.71-3.04)$. The risk did not increase with each additional comorbid condition. Evidence for the association of dementia and hospitalisation risk at the end of life was low strength. People with dementia near end of life are usually very ill with multiple health problems, but families caring for someone with dementia at the end of life may wish to avoid hospitalisation because of the distress it can cause, which could explain varying results.

The variation in findings on hospitalisation rates $(0.37$ to $1.17 /$ py) could be partly explained by the nature of the participant cohorts. Research cohort participants are often healthier than non-participants [53] and are subject to attrition of study participants; death is a common cause of attrition in studies of older populations [54]. Cohort studies may therefore become less representative over time and selectively include healthier participants. Lower hospitalisation rates could also be due to the method of outcome ascertainment, for example, asking family carers and patients about past admissions risks recall bias, whereas extracting data from a national database or register is likely to be more complete. Therefore, the highest rate of 1.17 admissions/py [43] may be the most reliable due to the large sample size and outcome derivation from a national register. Areas with more 
older people have lower emergency admission rates among older people [55] suggesting services are more integrated and prioritise community-based and ambulatory healthcare for older populations in these areas. Alternatively, there could be higher thresholds for emergency admissions due to the larger number of older people.

There is high confidence in the effect of older age, a risk factor which is unmodifiable. People with multimorbidities are unsurprisingly at higher risk of admission, but in one study, multimorbidity was associated with a higher risk of conditions judged as potentially manageable within primary care [12]. An earlier systematic review of reasons for admissions for people with dementia found that they are more likely to have been admitted to hospital for falls, fractures, and respiratory and urological infections than inpatients without dementia [56], so falls prevention and early recognition and management of respiratory and urinary tract infections and delirium may be valuable future intervention strategies. People with dementia often take many medications to manage existing comorbidities, and our study found moderate evidence that taking $\geq 7$ medications increases the risk of hospitalisation. The study examining polypharmacy adjusted for patient comorbidities, suggesting that medication use may contribute to elevated hospitalisation risk independent of multimorbidity; potentially inappropriate prescribing is common in older people without dementia and associated with a higher risk of hospitalisation [57]. Polypharmacy is a potentially modifiable risk factor, and while this may partially reflect the severity or number of illnesses a patient has, it may be that some of the drugs individually or when given together are causing more harm than good. It may be that medication is reviewed less in people with dementia, and they remain on medications when no longer needed. Drug interactions are more likely with each drug taken [58] and are more likely to be harmful in older patients [59]. Non-adherence to medications may mean that medication is judged to be ineffective and more is added, or a person with dementia may accidentally take too much medication; both could increase the risk of harmful drug interaction in this population. A recent randomised controlled trial indicated that communitybased deprescribing can be undertaken safely in older people without dementia, so it should be considered whether this could safely extend to people with dementia [60].

Having a lower functional ability was also associated with hospitalisation. Functional ability refers to basic tasks such as washing, and more intricate tasks such as cooking. In people with dementia, it can be difficult to ascertain whether loss of functionality is due to a combination of comorbidities, side effects of medication, or dementia. For instance, decreased ability to prepare food in people with dementia could lead to dangerous levels of malnutrition, dehydration, or weight loss [61], and therefore acute hospitalisation. Further loss of function could lead to an increase in the level of care needed to keep someone in the community and a decrease in the ability to seek and use appropriate help. Regarding dementia severity, we had moderate confidence that this was not associated, suggesting that it is a combination of physical and cognitive impairment and lack of external support, which increases admission risk, rather than cognitive impairment alone.

In addition to the risk posed by each individual risk factor, factors may interact with each other. It might be expected that people with dementia and at least one other comorbid condition are older than those with no comorbidities, take medication for their illnesses, and have a lower functional ability, therefore increasing their hospitalisation risk. Other studies have found that polypharmacy alone is associated with detrimental effects on functioning [62], which could further increase the risk of hospitalisation in this population. Rudolph et al. [37] discuss the theory of a multiplicative effect of risk factors and suggest patients with more than one risk factor comprise a high-risk group should be prioritised as recipients of future interventions to reduce hospitalisation.

\section{Strengths and limitations}

The comprehensive data search and thorough methodology of this review avoids subjectivity of data extraction and limits the risk of significant evidence being missed. During the initial screening process, a sample of eligible papers was reviewed independently by a second researcher to ensure the robustness of the application of inclusion criteria. Similarly, the risk of bias was reviewed independently by a second researcher, and grades of evidence were based on research team consensus using the gold standard Cochrane approach. Our use of the PRISMA checklist ensured standardised reporting [18].

This review has limitations which mainly relate to the limitations of included studies. We were only able to examine papers from some countries, and different patterns of admission may exist elsewhere in the world. Studies of solely care home populations were excluded; therefore, the results are not generalizable to those living in long-term care and may only be applicable to community-dwellers. However, as two thirds of people with dementia live in the community [9], the results have the potential to inform care of a large proportion of the people currently living with dementia. In addition, we did not include studies whose population consisted of hospitalised patients, as they were already likely to be more unwell than those in the community. We therefore 
expected that re-admission rates would be higher in this patient group and risk factors for re-admission may differ from those for the first admission, and therefore not apply to the wider community-dwelling population. However, some risk factors for readmission reported in other studies may apply to the first hospitalisation. When extracting the results, we focussed on "all-cause" hospitalisation and used the definition of hospitalisation provided by each study and studies may have defined this differently. Similarly, we used data for "avoidable" hospitalisation when all-cause hospitalisation data was not provided, and these definitions differed between studies. Avoidable admissions were termed "primary care sensitive" by Pimouguet, "ambulatory care sensitive" by Thorpe, "preventable" by Bynum, and "unplanned" or emergency by Mueller and Sommerlad [11, 12, 34, 41, 52]. Exactly which conditions fall into these categories varies, although there is a consensus that it comprises conditions which could be treated in the home or by primary care. It may be that only a rigorous randomised controlled trial with a well-designed intervention can determine the extent to which admissions are avoidable. Potential risk factors were classified in different ways between included studies, which prohibited combining estimates using meta-analysis. Finally, all non-randomised studies are susceptible to selection bias and residual confounding, so causality cannot be proven from observational studies.

\section{Conclusions}

This review finds hospital admission rates among people with dementia to be between $0.37 /$ py and $1.17 /$ py and strong evidence that people with dementia have 1.42 times higher risk of hospitalisation compared to people without dementia. Our evidence on admission rates of people with dementia informs policymakers aiming to ensure appropriate current and future provision of hospital care for people with dementia. Our study identifies people with dementia at high risk of hospitalisationthose who are older with physical comorbidities-and suggests that reducing polypharmacy and ameliorating functional impairment potentially will reduce admission risk. This informs clinicians treating people with dementia and future interventions aiming to reduce hospitalisation of people with dementia. There are indications of other potentially modifiable hospitalisation risk factors, but we were unable to make confident conclusions so rated them as low or very low due to the lack of evidence; these may warrant further detailed research. Identifying modifiable risk factors for hospital admission and devising effective approaches to address these have huge potential to improve the lives of people affected by dementia.

\section{Additional files}

Additional file 1: Table S1. Full list of search terms. Table S2. Full data extracted from included studies and full references. Table S3. Quality rating criteria and scores for included studies. Table S4. Risk of hospitalisation in people with dementia compared to people without dementia: full details of GRADE rating of evidence strength. Table S5. Percentage of study participants hospitalised in the study period. Table S6. Association of potential risk factors with hospitalisation in people with dementia: full details of GRADE rating of evidence strength for risk factors. (DOCX $147 \mathrm{~kb}$ )

Additional file 2: Study protocol. (PDF $100 \mathrm{~kb}$ )

\section{Abbreviations}

ACSC: Ambulatory care-sensitive conditions; Cl: Confidence interval; GRADE: Grading of Recommendations, Assessment, Development and Evaluation; HR: Hazard ratio; NOS: Newcastle-Ottawa Scale; OR: Odds ratio; Py: Person-years; RR: Relative risk

\section{Acknowledgements \\ None}

\section{Authors' contributions}

$A S$ and GL conceived the idea for this study. HS conducted the search. HS, $A S$, and $G L$ interpreted the data and drafted the manuscript and figures. JC conducted the quality check on inclusion criteria. AS performed the statistical tests. All authors read and approved the final manuscript.

\section{Funding}

This work was supported by the University College London Dementia Scholarship 2017 (HS) and a grant from the Wellcome Trust (200163/Z/15/Z) (AS). AS and GL are supported by the University College London Hospitals NIHR Biomedical Research Centre.

The authors analysed the results and prepared this manuscript independently of the funding bodies. The views and opinions expressed therein are those of the authors and do not necessarily reflect those of the NHS, the NIHR, or the Wellcome Trust. The funders had no role in the study design, data collection and analysis, decision to publish, or preparation of the manuscript.

\section{Availability of data and materials}

All data generated or analysed during this study are included in the published articles and its additional files.

Ethics approval and consent to participate

No ethical approval was required for this systematic review of existing published literature.

\section{Consent for publication}

Not applicable

\section{Competing interests}

All authors have completed the ICMJE uniform disclosure form at http:// www.icmje.org/conflicts-of-interest/ and declare HS reports funds from the UCL Dementia Scholarship 2017. GL has grants from the National Institute for Health Research (NIHR)/Economic and Social Research Council, NIHR Health Technology Assessment and Alzheimer's Society and is supported by the North Thames NIHR Collaboration for Leadership in Applied Health Research and Care. AS reports grants from the Wellcome Trust. GL and AS are supported by the University College London Hospitals NIHR Biomedical Research Centre.

Received: 28 March 2019 Accepted: 14 June 2019

Published online: 15 July 2019

\section{References}

1. Livingston G, Sommerlad A, Orgeta V, Costafreda SG, Huntley J, Ames D, et al. Dementia prevention, intervention, and care. Lancet. 2017:390:2673734. https://doi.org/10.1016/S0140-6736(17)31363-6. 
2. Lichtner V, Dowding D, Allcock N, Keady J, Sampson EL, Briggs M, et al The assessment and management of pain in patients with dementia in hospital settings: a multi-case exploratory study from a decision making perspective. BMC Health Serv Res. 2016;16:427. https://doi.org/10.1186/ s12913-016-1690-1.

3. White $\mathrm{N}$, Leurent B, Lord K, Scott S, Jones L, Sampson EL. The management of behavioural and psychological symptoms of dementia in the acute general medical hospital: a longitudinal cohort study. Int J Geriatr Psychiatry. 2017;32:297-305. https://doi.org/10.1002/gps.4463.

4. D JR, NO A, Ó-R C, J C, M L, J MF, et al. Delirium in an adult acute hospital population: predictors, prevalence and detection 2012. https://doi.org/10. 1136/bmjopen-2012.

5. Sager MA, Rudberg MA, Jalaluddin M, Franke T, Inouye SK, Landefeld CS, et al. Hospital Admission Risk Profile (HARP): identifying older patients at risk for functional decline following acute medical illness and hospitalization. J Am Geriatr Soc. 1996;44:251-7. https://doi.org/10.1111/j.1532-5415.1996. tb00910.x.

6. Wolf D, Rhein C, Geschke K, Fellgiebel A. Preventable hospitalizations among older patients with cognitive impairments and dementia. Int Psychogeriatrics. 2018:1-9. https://doi.org/10.1017/S1041610218000960.

7. Pickens S, Naik AD, Catic A, Kunik ME. Dementia and hospital readmission rates: a systematic review. Dement Geriatr Cogn Dis Extra. 2017;7:346-53. https://doi.org/10.1159/000481502.

8. Zhu CW, Cosentino S, Ornstein K, Gu Y, Scarmeas N, Andrews H, et al. Medicare utilization and expenditures around incident dementia in a multiethnic cohort. J Gerontol A Biol Sci Med Sci. 2015;70:1448-53. https:// doi.org/10.1093/gerona/glv124.

9. Department of Health. Living well with dementia: a National Dementia Strategy 2009.

10. Phelan EA, Debnam KJ, Anderson LA, Owens SB. A systematic review of intervention studies to prevent hospitalizations of community-dwelling older adults with dementia. Med Care. 2015;53:207-13.

11. Pimouguet C, Rizzuto D, Fastbom J, Lagergren M, Fratiglioni L, Xu W. Influence of incipient dementia on hospitalization for primary care sensitive conditions: a population-based cohort study. J Alzheimers Dis. 2016;52:21322. https://doi.org/10.3233/JAD-150853.

12. Thorpe J, Van Houtven C, Sleath B, Thorpe C. Rural-urban differences in preventable hospitalizations among community-dwelling veterans with dementia. J Rural Health. 2010;26:146-55. https://doi.org/10.1111/j.17480361.2010.00276.x

13. Wells G, Shea B, O'Connell D, Peterson J, Welch V, Losos M, et al. NewcastleOttawa quality assessment scale case control studies 2014

14. Iorio A, Spencer FA, Falavigna M, Alba C, Lang E, Burnand B, et al. Use of GRADE for assessment of evidence about prognosis: rating confidence in estimates of event rates in broad categories of patients. BMJ. 2015:350:h870. https://doi.org/10.1136/BMJ.H870

15. Begg CB, Mazumdar M. Operating characteristics of a rank correlation test for publication bias. Biometrics. 1994;50:1088-101.

16. DerSimonian R, Laird N. Meta-analysis in clinical trials. Control Clin Trials. 1986;7:177-88. https://doi.org/10.1016/0197-2456(86)90046-2.

17. Fu R, Gartlehner G, Grant M, Shamliyan T, Sedrakyan A, Wilt TJ, et al. Conducting quantitative synthesis when comparing medical interventions: AHRQ and the effective health care program. J Clin Epidemiol. 2011;64: 1187-97. https://doi.org/10.1016/j.jclinepi.2010.08.010.

18. Moher D, Liberati A, Tetzlaff J, Altman DG. Preferred Reporting Items for Systematic Reviews and Meta-Analyses: the PRISMA statement. PLoS Med. 2009;6(7):E1000097. https://doi.org/10.1371/journal.pmed1000097.

19. Albert SM, Costa R, Merchant C, Small S, Jenders RA, Stern Y. Hospitalization and Alzheimer's disease: results from a community-based study. J Gerontol A Biol Sci Med Sci. 1999;54:M267-71.

20. Aupperle P, Coyne A. Primary vs subspecialty care: a structured follow-up of dementia patients and their caregivers. Am J Geriatr Psychiatry. 2000;8:16770

21. Browne J, Edwards D, Rhodes K, Brimicombe D, Payne R. Association of comorbidity and health service usage among patients with dementia in the UK: a population-based study. BMJ Open. 2017;7:e012546. https://doi.org/10 1136/bmjopen-2016-012546.

22. Brüggenjürgen B, Andersohn F, Ezzat N, Lacey L, Willich S. Medical management, costs, and consequences of Alzheimer's disease in Germany: an analysis of health claims data. J Med Econ. 2015;18:466-73. https://doi. org/10.3111/13696998.2015.1014090.
23. Bynum JPW, Rabins PV, Weller W, Niefeld M, Anderson GF, Wu AW. The relationship between a dementia diagnosis, chronic illness, medicare expenditures, and hospital use. J Am Geriatr Soc. 2004;52:187-94.

24. Callahan C, Arling G, Tu W, Rosenman M, Counsell S, Stump T, et al. Transitions in care for older adults with and without dementia. J Am Geriatr Soc. 2012;60:813-20. https://doi.org/10.1111/j.1532-5415.2012. 03905.x

25. Chen L, Reed C, Happich M, Nyhuis A, Lenox-Smith A. Health care resource utilisation in primary care prior to and after a diagnosis of Alzheimer's disease: a retrospective, matched case-control study in the United Kingdom. BMC Geriatr 2014;14:76. https://doi.org/10.1186/1471-2318-14-76.

26. Cortes F, Nourhashémi F, Guérin O, Cantet C, Gillette-Guyonnet S, Andrieu S, et al. Prognosis of Alzheimer's disease today: a two-year prospective study in 686 patients from the REAL-FR study. Alzheimers Dement. 2008;4:22-9. https://doi.org/10.1016/j.jalz.2007.10.018.

27. Hill J, Fillit H, Shah SN, Del Valle MC, Futterman R. Patterns of healthcare utilization and costs for vascular dementia in a community-dwelling population. J Alzheimers Dis. 2005;8:43-50. https://doi.org/10.3233/JAD2005-8105.

28. Jennings LA, Laffan AM, Schlissel AC, Colligan E, Tan Z, Wenger NS, et al. Health Care Utilization and Cost Outcomes of a Comprehensive Dementia Care Program for Medicare Beneficiaries. JAMA Intern Med. 2019;179:161-6. https://doi.org/10.1001/jamainternmed.2018.5579.

29. Kunik ME, Snow AL, Molinari VA, Menke TJ, Souchek J, Sullivan G, et al. Health care utilization in dementia patients with psychiatric comorbidity. Gerontologist. 2003;43:86-91.

30. Malone DC, McLaughlin TP, Wahl PM, Leibman C, Arrighi HM, Cziraky MJ, et al. Burden of Alzheimer's disease and association with negative health outcomes. Am J Manag Care. 2009;15:481-8.

31. Maust D, Kales H, McCammon R, Blow F, Leggett A, Langa K. Distress Associated with Dementia-Related Psychosis and Agitation in Relation to Healthcare Utilization and Costs. Am J Geriatr Psychiatry 2017;25:1074-82. https://doi.org/10.1016/j.jagp.2017.02.025.

32. Miu D, Ying $K, H$ k M, Uk M, Cuhk MPH, Edin F, et al. Hospital admission risk in community dwelling elderly dementia subjects. 2018;9:39-43. https://doi. org/10.24816/jcgg.2018.v9i2.02

33. Mueller C, Perera G, Rajkumar A, Bhattarai M, Price A, O'Brien J, et al. Hospitalization in people with dementia with Lewy bodies: Frequency, duration, and cost implications. Alzheimer's Dement Diagnosis, Assess Dis Monit 2017;10:143-52. https://doi.org/10.1016/j.dadm.2017.12.001

34. Mueller C, Molokhia M, Perera G, Veronese N, Stubbs B, Shetty H, et al. Polypharmacy in people with dementia: associations with adverse health outcomes. Exp Gerontol. 2018;106:240-5. https://doi.org/10.1016/j.exger. 2018.02.011.

35. Nourhashemi F, Amouyal-Barkate K, Gillette-Guyonnet S, Cantet C, Vellas B. Living alone with Alzheimer's disease: cross-sectional and longitudinal analysis in the REAL.FR study. J Nutr Health Aging. 2005;9:117-20.

36. Phelan EA, Borson S, Grothaus L, Balch S, Larson EB. Association of incident dementia with hospitalizations. JAMA 2012;307:165-72. https://doi.org/10. 1001/jama.2011.1964

37. Rudolph J, Zanin N, Jones R, Marcantonio E, Fong T, Yang F, et al. Hospitalization in community-dwelling persons with Alzheimer's disease: frequency and causes. J Am Geriatr Soc. 2010;58:1542-8. https://doi.org/10. 1111/j.1532-5415.2010.02924.x.

38. Russ T, Parra M, Lim A, Law E, Connelly P, Starr J. Prediction of general hospital admission in people with dementia: cohort study. Br J Psychiatry. 2015;206:153-9. https://doi.org/10.1192/bjp.bp.113.137166.

39. Sköldunger A, Fastbom J, Wimo A, Fratiglioni L, Johnell K. Impact of inappropriate drug use on hospitalizations, mortality, and costs in older persons and persons with dementia: findings from the SNAC Study. Drugs Aging. 2015;32:671-8. https://doi.org/10.1007/s40266-015-0287-4.

40. Sloane P, Schifeling C, Beeber A, Ward K, Reed D, Gwyther L, et al. New or worsening symptoms and signs in community-dwelling persons with dementia: incidence and relation to use of acute medical services. J Am Geriatr Soc. 2017;65:808-14. https://doi.org/10.1111/jgs.14672.

41. Sommerlad A, Perera G, Mueller C, Singh-Manoux A, Lewis G, Stewart R, et al. Hospitalisation of people with dementia: evidence from English electronic health records from 2008 to 2016. Eur J Epidemiol. 2019. https:// doi.org/10.1007/s10654-019-00481-X.

42. Soto M, Andrieu S, Gares V, Cesari M, Gillette-Guyonnet S, Cantet C, et al. Living alone with alzheimer's disease and the risk of adverse outcomes: 
Results from the plan de soin et d'aide dans la maladie d'alzheimer study. J Am Geriatr Soc. 2015;63:651-8. https://doi.org/10.1111/jgs.13347

43. Tolppanen A-M, Taipale H, Purmonen T, Koponen M, Soininen H, Hartikainen S. Hospital admissions, outpatient visits and healthcare costs of community-dwellers with Alzheimer's disease. Alzheimers Dement. 2015;11: 955-63. https://doi.org/10.1016/j.jalz.2014.10.005.

44. Zhao Y, Kuo T-C, Weir S, Kramer MS, Ash AS. Healthcare costs and utilization for Medicare beneficiaries with Alzheimer's. BMC Health Serv Res. 2008;8: 108. https://doi.org/10.1186/1472-6963-8-108.

45. Zhu C, Cosentino S, Ornstein K, Gu Y, Andrews H, Stern Y. Use and cost of hospitalization in dementia: Iongitudinal results from a community-based study. Int J Geriatr Psychiatry. 2015;30:833-41. https://doi.org/10.1002/gps.4222.

46. Axmon A, Karlsson B, Ahlstrom G. Health care utilisation among older persons with intellectual disability and dementia: a registry study. J Intellect Disabil Res. 2016;60:1165-77. https://doi.org/10.1111/jir.12338.

47. Chen YH, Ho CH, Huang CC, Hsu YW, Chen YC, Chen PJ, et al. Comparison of healthcare utilization and life-sustaining interventions between elderly patients with dementia and those with cancer near the end of life: a nationwide, population-based study in Taiwan. Geriatr Gerontol Int. 2017;17: 2545-51. https://doi.org/10.1111/ggi.13084.

48. Forma L, Rissanen P, Aaltonen M, Raitanen J, Jylhä M. Dementia as a determinant of social and health service use in the last two years of life 1996-2003. BMC Geriatr. 2011;11:14. https://doi.org/10.1186/1471-2318-1114.

49. Kedia S, Chavan P, Boop S, Yu X. Health Care Utilization Among Elderly Medicare Beneficiaries With Coexisting Dementia and Cancer. Gerontol Geriatr Med. 2017;3:233372141668904. https://doi.org/10.1177/ 2333721416689042.

50. Tian H, Abouzaid S, Sabbagh M, Chen W, Gabriel S, Kahler K, et al. Health care utilization and costs among patients with $\mathrm{AD}$ with and without dysphagia. Alzheimer Dis Assoc Disord. 2013;27:138-44. https://doi.org/10 1097/WAD.0b013e318258cd7d.

51. Zhu CW, Scarmeas N, Ornstein K, Albert M, Brandt J, Blacker D, et al. Healthcare use and cost in dementia caregivers: longitudinal results from the Predictors Caregiver Study. Alzheimers Dement. 2015;11:444-54. https://doi. org/10.1016/j.jalz.2013.12.018

52. Bynum J, Rabins P, Weller W, Niefeld M, Anderson G, Wu A, et al. Illness, Medicare expenditures, and hospital use. J Am Geriatr Soc. 2004;52:187-94. https://doi.org/10.1111/j.1532-5415.2004.52054.x.

53. Mann C. Observational research methods. Research design II: cohort, cross sectional, and case-control studies. EMJ. 2003:54-60.

54. Brilleman SL, Pachana NA, Dobson AJ. The impact of attrition on the representativeness of cohort studies of older people. BMC Med Res Methodol. 2010;10. https://doi.org/10.1186/1471-2288-10-71.

55. Imison C, Poteliakhoff E, Thompson J. Older people and emergency bed use. Exploring variation. Ideas That Chang Healthc. 2012:1-24. https://doi. org/10.1136/emermed-2012-201867.

56. Toot S, Devine M, Akporobaro A, Orrell M. Causes of hospital admission for people with dementia: a systematic review and meta-analysis. J Am Med Dir Assoc. 2013;14:463-70. https://doi.org/10.1016/j.jamda.2013.01.011.

57. Pérez T, Moriarty F, Wallace E, McDowell R, Redmond P, Fahey T. Prevalence of potentially inappropriate prescribing in older people in primary care and its association with hospital admission: longitudinal study. BMJ. 2018;363: k4524. https://doi.org/10.1136/BMJ.K4524.

58. Shi $\mathrm{S}$, Mörike $\mathrm{K}$, Klotz $\mathrm{U}$. The clinical implications of ageing for rational drug therapy. Eur J Clin Pharmacol. 2008;64:183-99. https://doi.org/10.1007/ s00228-007-0422-1.

59. Herrlinger C, Klotz U. Drug metabolism and drug interactions in the elderly. Bailliere's Best Pract Res Clin Gastroenterol. 2001;15:897-918. https://doi.org/ 10.1053/bega.2001.0249.

60. Martin P, Tamblyn R, Benedetti A, Ahmed S, Tannenbaum C. Effect of a pharmacist-led educational intervention on inappropriate medication prescriptions in older adults. JAMA. 2018;320:1889. https://doi.org/10.1001/ jama.2018.16131.

61. Holm B, Söderhamn O. Factors associated with nutritional status in a group of people in an early stage of dementia. Clin Nutr. 2003;22:385-9. https:// doi.org/10.1016/S0261-5614(03)00035-9.

62. Clague F, Mercer SW, Mclean G, Reynish E, Guthrie B. Comorbidity and polypharmacy in people with dementia: insights from a large, populationbased cross-sectional analysis of primary care data. Age Ageing. 2017:46:339. https://doi.org/10.1093/ageing/afw176.

\section{Publisher's Note}

Springer Nature remains neutral with regard to jurisdictional claims in published maps and institutional affiliations.
Ready to submit your research? Choose BMC and benefit from:

- fast, convenient online submission

- thorough peer review by experienced researchers in your field

- rapid publication on acceptance

- support for research data, including large and complex data types

- gold Open Access which fosters wider collaboration and increased citations

- maximum visibility for your research: over $100 \mathrm{M}$ website views per year

At BMC, research is always in progress.

Learn more biomedcentral.com/submissions 